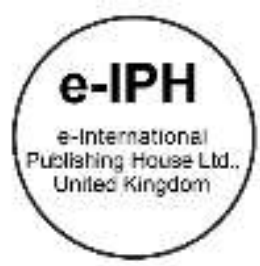

\title{
Stay Activities on Car-free Neighborhood Shopping Streets
}

\author{
Anthony Murithi Njeru ${ }^{1}$, Isami Kinoshita ${ }^{2}$ \\ 1 Graduate School of Horticulture, Chiba University, 648 Matsudo City, 271-8510, Japan \\ Afta8857@chiba-u.jp, isamikinoshita@faculty.chiba-u.jp \\ Tel: +81473088790
}

\begin{abstract}
This paper evaluates the occurrence of stay activities such as sitting and children's play in two neighborhood shopping streets in the Tokyo Metropolitan area through direct observation and mapping. Results reveal the dominance of mobility on weekdays with cars, the rarity of stay activities on ordinary car-free Sundays, and the upsurge of stay activities during organized street events. Finally, the study discusses the key trends in the occurrence of stay activities, the significance of organized activities such as playstreet and music performances, innovative use of street elements, and the influence of adjacent stores on the liveliness of the streets.
\end{abstract}

Keywords: Car-free, Streets, Neighborhood, Stay Activities

eISSN: 2398-4287 @ 2018. The Authors. Published for AMER ABRA cE-Bs by e-International Publishing House, Ltd., UK. This is an open access article under the CC BYNC-ND license (http://creativecommons.org/licenses/by-nc-nd/4.0/). Peer-review under responsibility of AMER (Association of Malaysian Environment-Behaviour Researchers), ABRA (Association of Behavioural Researchers on Asians) and cE-Bs (Centre for Environment-Behaviour Studies), Faculty of Architecture, Planning \& Surveying, Universiti Teknologi MARA, Malaysia.

https://doi.org/10.21834/e-bpj.v3i9.1527

\subsection{Background}

Across the Tokyo Metropolitan Area, restriction of cars in the evenings and weekends on shopping streets has been a common phenomenon for decades in attempts at transforming streets into public open spaces that guarantee the safety of pedestrians and allow for a more relaxed shopping experience. From previous studies, liveliness brought by pedestrians is key to the survival of shopping streets. Meanwhile, aspects of street safety, comfort, and connectivity are key determinants of pedestrians' perceptions of street spaces and the eventual liveliness (Zakaria \& Ujang, 2015). Whereas the smooth flow of pedestrians' is critical, the amount of stay activities such as sitting and children's play is a key indicator of the quality of a street space (Mehta, 2014; Gehl, 2011). Unfortunately, there are minimal stay activities on most shopping streets in Japan during car-free hours; use of these spaces is generally limited to mobility. However, there are interspersed organized activities such as play street and music performances that intervene in the normal flow of activities on these streets and unearth the value of streets as public open spaces.

This study aimed at clarifying the factors that contribute to the use of streets for stay activities in car-free streets, and the significance of organized events. Observations conducted on Wednesdays sought to bring an understanding on sidewalk use behavior on weekdays when cars traverse the street. Observations conducted on car-free Sundays are geared at explaining how people utilize streets as public open spaces in the absence of cars.

\subsection{Literature Review}

Making of public spaces is not limited to the physical environment and provision of physical infrastructure; success depends on the ability to support people's activities activity and sociability (Carlin, 2014; Hou, 2012). The collaborative process and exchange among various actors on the streets is crucial in the production of street spaces where these actions occur (Carlin, 2014). Gehl (2011) categorizes outdoor activities in public spaces into three major categories: necessary activities such as shopping or waiting for a bus, 2. Optional activities such as strolling or standing to enjoy life, and 3., Social activities such as children play, greetings and conversations. The character of the physical environment is of little influence to the necessary activities compared to optional activities; however, the

eISSN: 2398-4287 @ 2018. The Authors. Published for AMER ABRA cE-Bs by e-International Publishing House, Ltd., UK. This is an open access article under the CC BYNC-ND license (http://creativecommons.org/licenses/by-nc-nd/4.0/). Peer-review under responsibility of AMER (Association of Malaysian Environment-Behaviour Researchers), ABRA (Association of Behavioural Researchers on Asians) and cE-Bs (Centre for Environment-Behaviour Studies), Faculty of Architecture, Planning \& Surveying, Universiti Teknologi MARA, Malaysia.

https://doi.org/10.21834/e-bpj.v3i9.1527 
social activities depend on the presence of other people. Peoples' positive perception of streets is a factor of the physical environment (e.g. landscape features, access, and legibility), activities therein (e.g. entertainment and presence of vendors), and the individual feelings or mental images that people have regarding the place (see Ja'afar, Sulaiman \& Shamsuddin, 2018; Ujang, 2017; Chen, Nakamura \& Kuma, 2014). Other studies have also demonstrated the influence of business types in determining the atmosphere of a street (see Lee and Yoon, 2015).

To measure the success of streets as open spaces, Mehta (2014) proposes five aspects: 1. Inclusiveness (e.g. presence of people of diverse genders, race, and class, and the range of activities and behaviors), 2. Meaningful activities (e.g. variety of businesses on the edges and the availability of food within or on the edges of the space), 3. Comfort (e.g. shade, shelter, and places to sit without paying for goods or services) 4. Safety (e.g. openness to adjacent streets and safety from traffic), and 5. Pleasurability (e.g. presence of memorable landscape features). Gehl and Svarre (2013) advocate for five aspects in evaluating a space: How many people, who (for example men, women, and children), where, what the person is doing, and how long the activities take.

\subsection{Methodology}

This study relied on structured and unstructured observation techniques to describe the nature and location of stay activities on two streets. Direct observation of human behavior allows for an understanding of the reality of how people use spaces in their day-today life and the objective examination of why some spaces work while others do not (Gehl \& Svarre, 2013; Whyte, 1980).

\subsection{The study areas}

Chuo-dori street in Mitaka city and Howdy-mall in Kashiwa city were selected for this study. The two streets host infrequent organized activities such as play street. Both streets are situated in mixed-use neighborhoods and are dominated by basic establishments such as restaurants, convenience stores, and boutiques although they host other land uses such as residential apartments and banks; they are also connected to major train stations (figure 3.1 and 3.2). The two neighborhoods are also regarded as bed towns for people working in central Tokyo although they have other land uses.

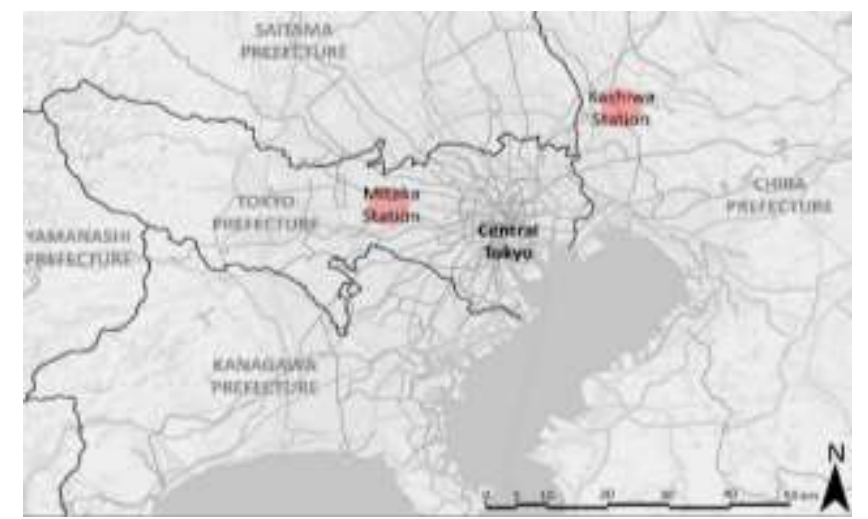

Figure 3.1: Contextual location of the case studies in relation to Central Tokyo. Source Author; adapted from Google Maps
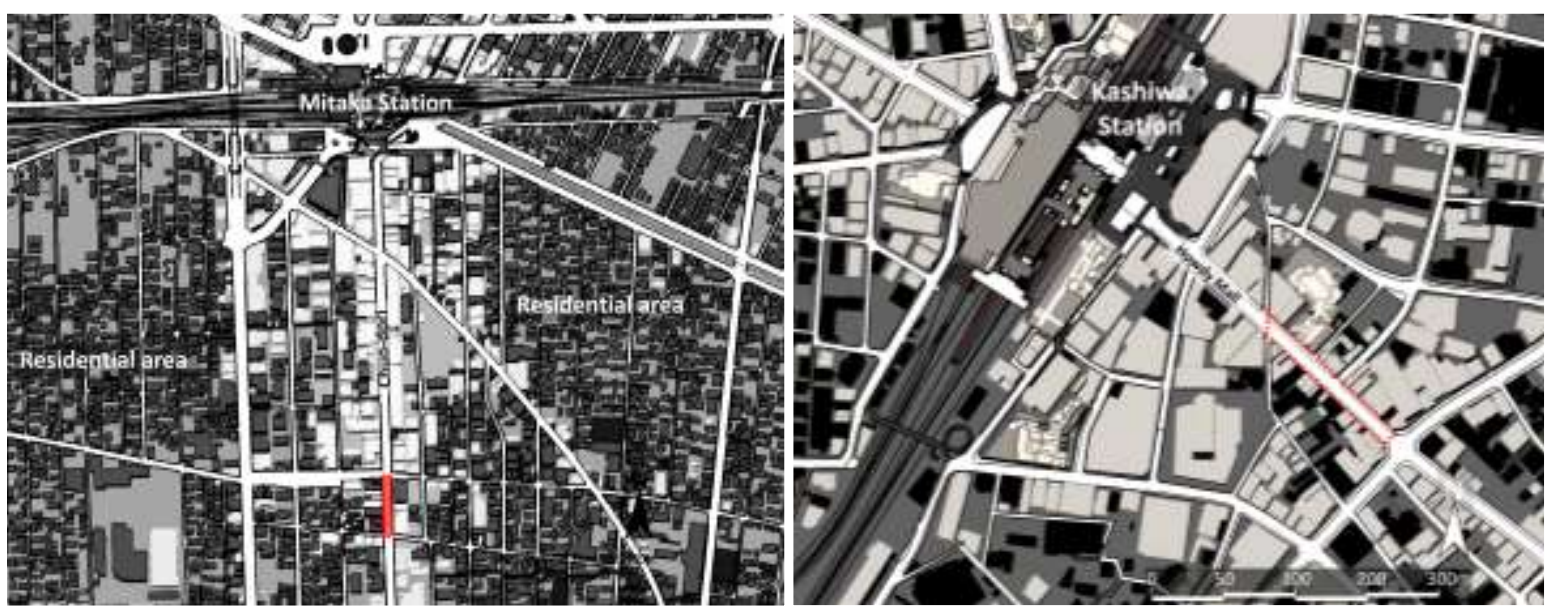

Figure 3.2: Location of Chuo-dori (left) and Howdy Mall (right) relative to Mitaka and Kashiwa Stations respectively Source: Author; adapted from Google Maps 


\subsection{Observation period}

Observations were done every fifteen minutes from 1300hrs to 1600hrs, between Spring and Autumn 2017 in good weather (table 3.1). This timing coincided with the common timing for organized street activities. This kind of focus is favorable in studies on outdoor activities that are concentrated at certain seasons and time of day (Abu-Ghazzeh, 1998; Mehta, 2007).

\begin{tabular}{llll} 
& \multicolumn{3}{c}{ Table 3.1: Observation schedule } \\
\hline Street name & Weekdays & $\begin{array}{l}\text { Ordinary Car-free } \\
\text { days }\end{array}$ & $\begin{array}{l}\text { Car-free Sundays with } \\
\text { organized activities }\end{array}$ \\
\hline Chuo-Dori & $2017-05-31$ & $2017-07-09$ & $2017-05-28$ \\
& $2017-06-07$ & $2017-07-23$ & $2017-08-27$ \\
& $2017-07-05$ & $2017-08-06$ & \\
Howdy Mall & & $2017-10-01$ & $2017-10-08$ \\
& & $2017-10-15$ & $2017-11-12$ \\
\hline \multicolumn{3}{c}{ Source; Author }
\end{tabular}

\subsection{Structured observation}

The location of stay activities was mapped on coding sheets of A3 paper using pre-planned symbols such as dots and crosses for the following activities: adult standing(o), adults in a conversation $(\bullet)$, adult sitting $(\mathrm{x})$, adult doing something $(\square)$, child sitting or standing $(\Delta)$, and child playing ( $(\mathbf{\Lambda})$. A total of 13 instances were recorded each day (every 15 minutes). During crowded events, photography was utilized to complement the manual recording. However, due to very low levels of stay activities in most days, many instances were combined into a single map for each case to easily visualize the constellation of activities.

Constellations of various stay activities, their trends and tendencies, and the associations between stay activities and physical surroundings were then identified. Examination of the physical characteristics that influence the location of stay activities on the street was also done.

\subsection{Unstructured observation}

Unstructured observation and note-taking were carried out during authors' participation in activities such as playstreet and music performances. This involved recording of conditions, behaviors and design characteristics of each street: the dimensions of the street, street furniture and other facilities, the character of on-street buildings, and the general upkeep of the street.

\subsection{Results}

\subsection{Stay Activities in Chuo-dori}

In general, unstructured observation showed that the appropriation of Chuo-dori on weekdays is founded on the respect for the car space, and the concentration on shopping activities; while the weekly restriction of cars improves spaciousness of the street, stay activities do not increase significantly expect on car-free days with organized activities (figure 4.1.1). On ordinary car-free Sundays, the space reclaimed from cars is taken by cyclists while stay activities remain aligned to the sides of the street.

From structured observation, among the six types of stay activities examined, weekdays and normal car-free days are dominated by standing while children play dominates during play events. Apart from the general increase in the number of people during events, the proportion of adults sitting, doing something, and children playing rises significantly (table 4.1.1). There are however very little emergent conversations among adults triggered by the organized events.

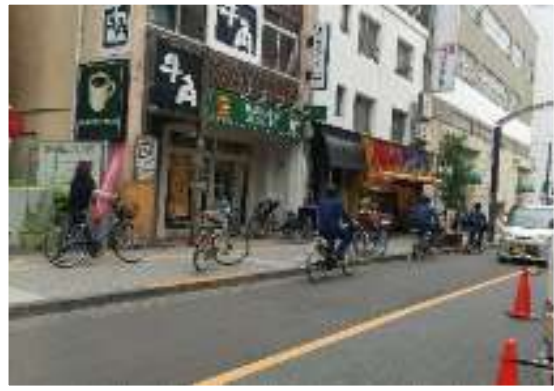

Figure 4.1.1: Chuo-dori street on weekdays with cars (left), ordinary car-free days (center), and orgar Source' Author
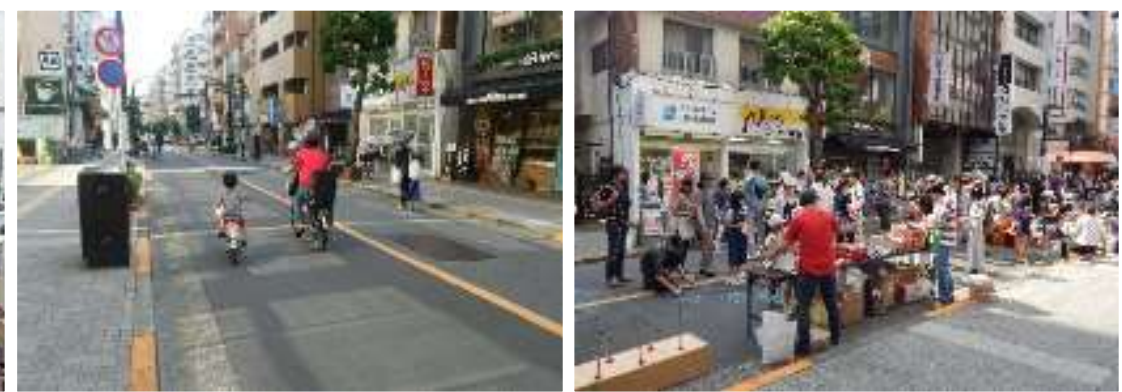

anized activities on a car-free Sunday (right) Without organized events, stay activities are generally tied to adjacent stores (figure 4.1.2) through aspects such as window
shopping, reading a menu, or buying meat from Andes shop that is open to the street. The constellation of people during car-free events is influenced by the activity at each station. For example, the huge congregation of children outside the Lifesalon insurance shop is influenced by the kind of play as well as the company's advertisement interests: children engage in play activities whose end is a gift 
while the staffs get an opportunity to advertise their products to parents and passers-by. The play station outside Puu no mori includes a picture-story show, kamishibai organized by puu no mori store that sells traditional children books. The characteristics of the top three storefronts that attracted constellation of stay activities are summarized in table 4.1.2. Additionally, events increase unconventional improvisation of street elements that is rare in other days (figure 4.1.3).

Table 4.1.1 variations in stay activities in chou-dori street

\begin{tabular}{lccccccccc}
\hline & Weekdays & \multicolumn{3}{c}{ Ordinary Car-free Sundays } & \multicolumn{3}{c}{ Car-free Sundays with } \\
organized activities
\end{tabular}

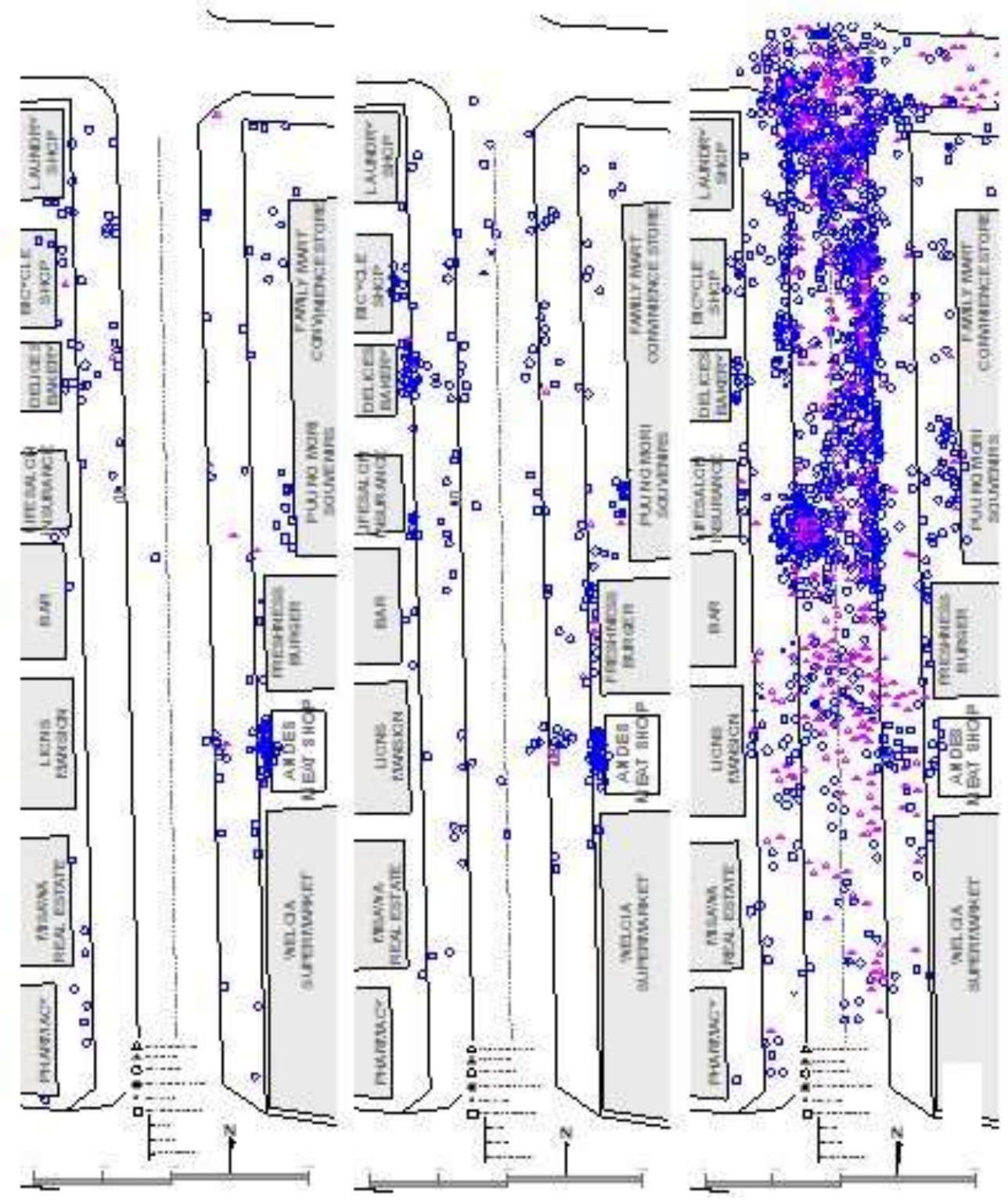

Figure 4.1.2: Mapping of activities on chou-dori. Weekdays (left), ordinary car-free days (center), and car-free Sundays with organized activities (right).

Source: Author 

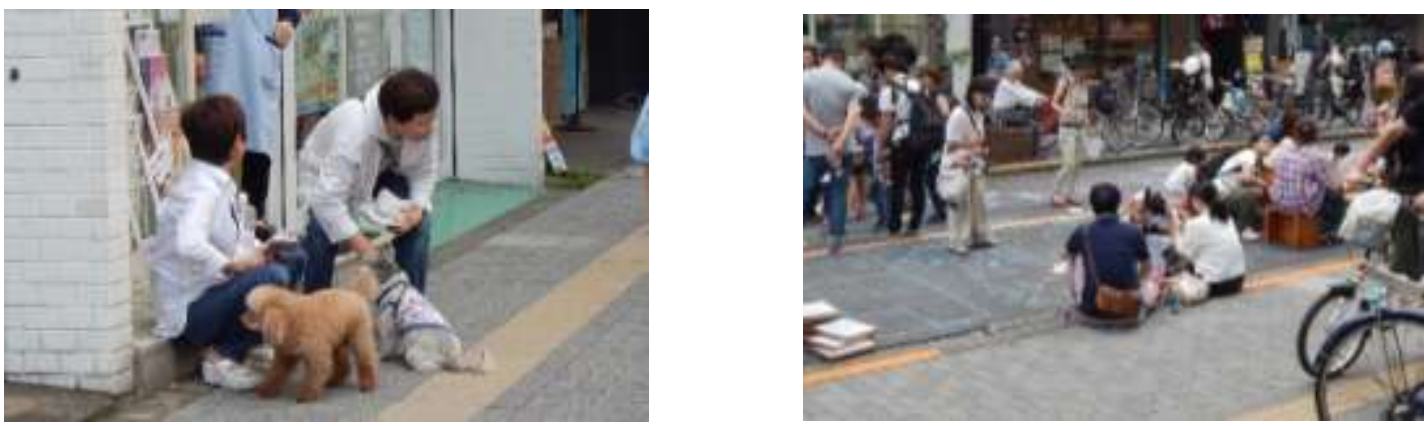

Figure 4.1.3: Emergent of unconventional use of street elements during organized events Source: Author

Table 4.1.2: Influence of stores on street activities

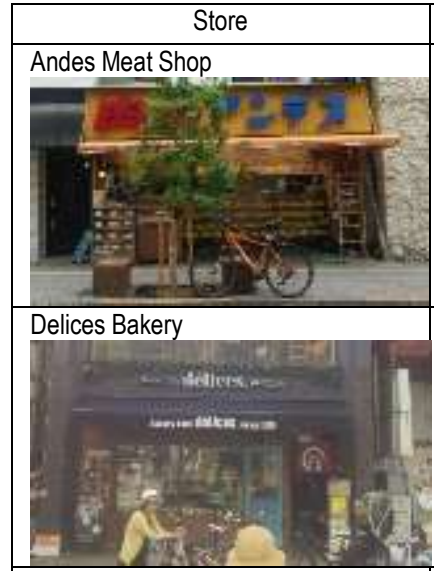
Reasons for attracting Stay Activities

Popular for various kinds of meat dishes such as fried chicken. The storefront is fully open to the street and people can buy or do window shopping while standing on the street or sitting on bicycles. The glass cased displays directly face the street, an attraction to passersby. The rest of the facade is brightly colored and labelled in big characters hence noticeable from far.

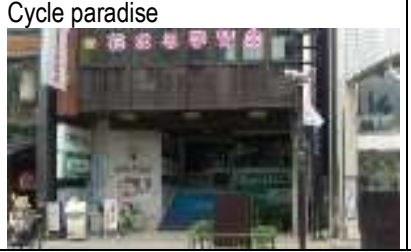

The transparency of the facades encourages congregation of people for short durations. Window shopping and reading the menu for the bakery or the bar upstairs increases the liveliness of the space. Due to its popularity with families, it is a major decision point as people discus the menus outside or wait for each other.

Although the permeability and personalization of the space is comparatively low, there are emergent conversations due to the building's function: cyclists talk among themselves as well as with the shop's staff. Additionally, the space is enhanced by the niche offset from the street that serves as a shaded standing space.

Source: Author

\subsection{Stay activities in Howdy Mall}

From unstructured observations, on weekdays when cars use the street, stay activities are minimal and limited to the sidewalk. On Sundays when the street is car-free, there is only a slight increase in the number of people using the central space. Major changes are only witnessed during organized activities such as music concerts as shown in figure 4.2.1

From structured observation, stay activities are dominated by adults standing. Sitting also increases significantly. However, the number of adults engaged in conversations has a marginal increase during events although they do other things during the events. Additionally, there is no significant increase in activities of children attributable to car-free street conditions or events as shown in table 4.21.

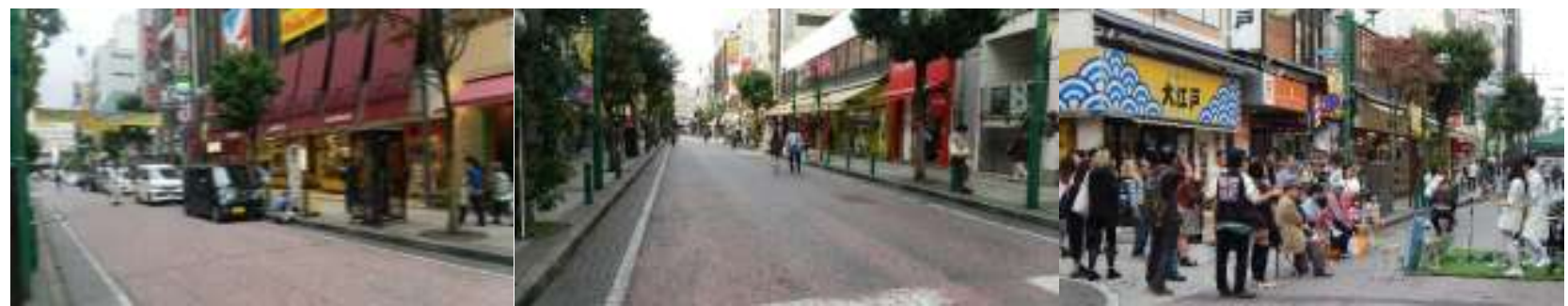

Figure 4.2.1: Howdy Mall's street's character and activities: Weekdays with cars (left), normal car-free Sunday, and an organized event on a car-free Sunday 
Table 4.2.1 variations in stay activities in howdy-mall street

\begin{tabular}{|c|c|c|c|c|c|}
\hline \multirow[b]{2}{*}{ Activity/Month-Date } & \multicolumn{2}{|c|}{$\begin{array}{c}\text { Ordinary Car-free } \\
\text { Sundays }\end{array}$} & \multicolumn{2}{|c|}{$\begin{array}{c}\text { Car-free Sundays with } \\
\text { organized activities }\end{array}$} & \multirow[b]{2}{*}{ Total Counts } \\
\hline & $10-01$ & $10-15$ & $10-08$ & $11-12$ & \\
\hline Standing & 137 & 106 & 205 & 231 & 679 \\
\hline Conversation & 5 & 26 & 44 & 26 & 101 \\
\hline Sitting & 11 & 0 & 34 & 52 & 97 \\
\hline Doing something & 3 & 3 & 28 & 44 & 78 \\
\hline Child Standing or sitting & 26 & 8 & 23 & 18 & 75 \\
\hline Child playing & 0 & 0 & 6 & 6 & 12 \\
\hline Total counts & 182 & 143 & 340 & 377 & \\
\hline
\end{tabular}

In ordinary car-free Sundays, constellations of people on the street are concentrated near particular establishments as shown in figure 4.2.2. There is also congregation of people around music performances (figure 4.2.3).

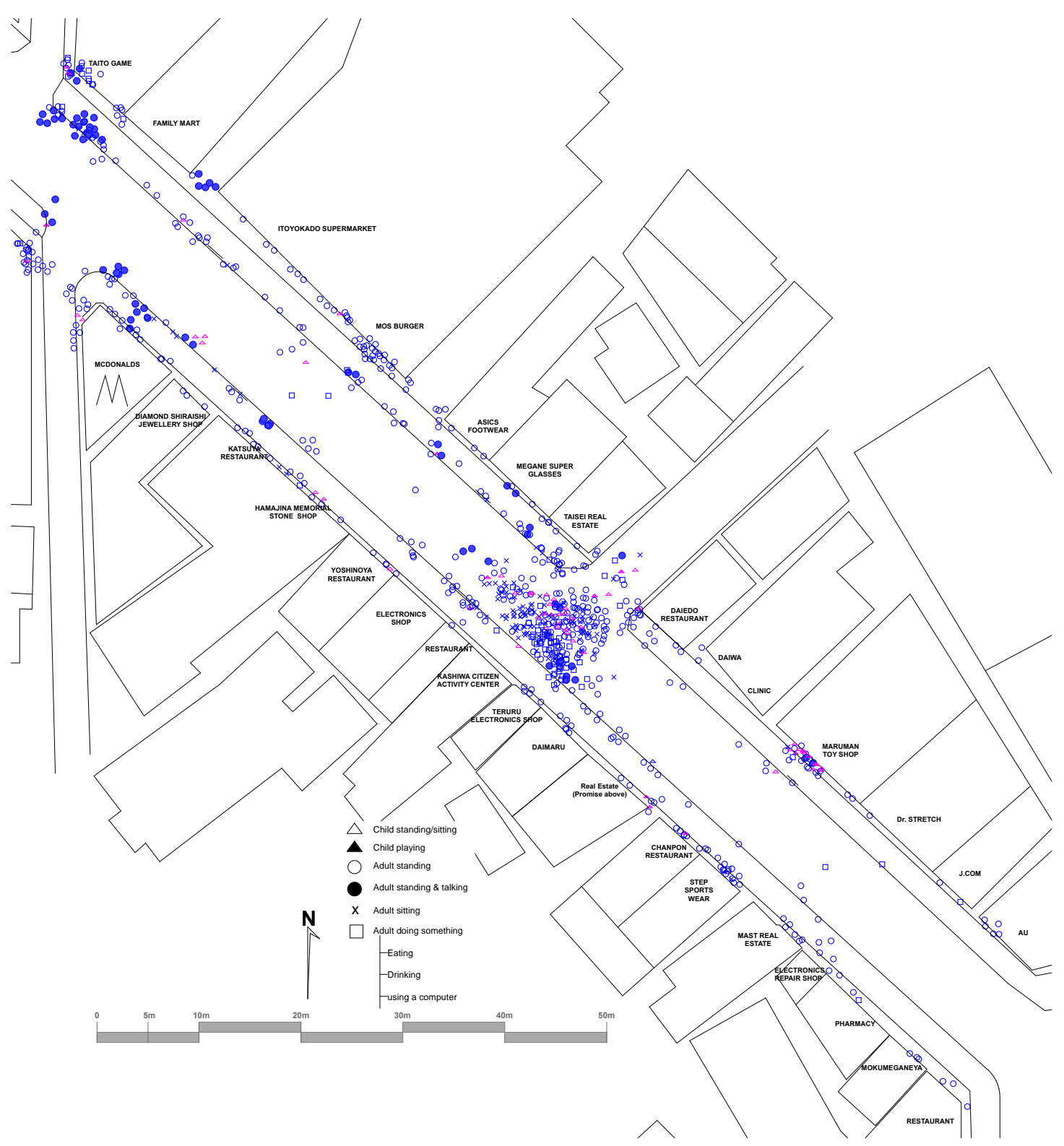

Figure 4.2.3: Stay activities in Howdy-mall on car-free Sundays with music concerts 


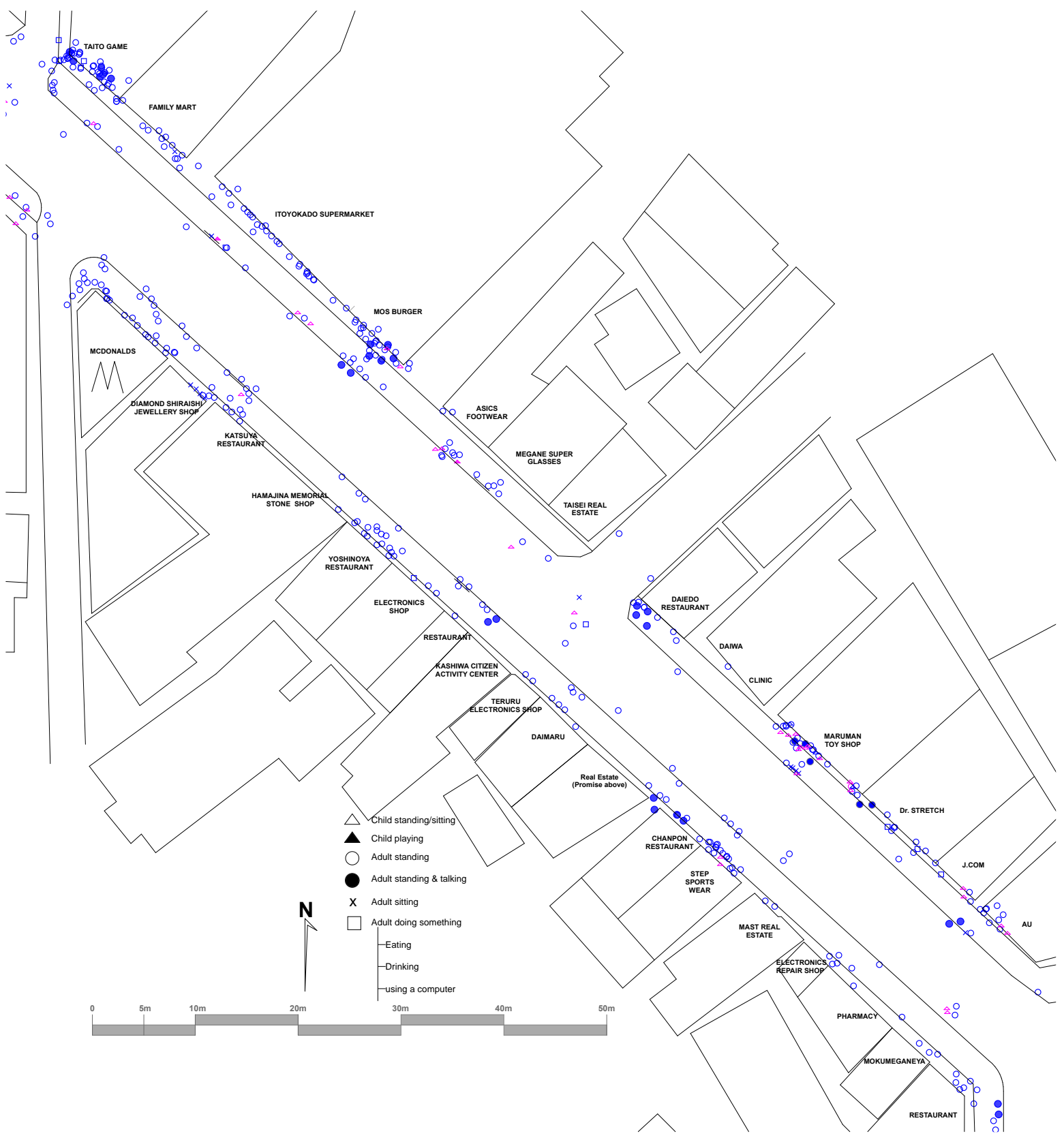

Figure 4.2.2: Stay activities in Howdy mall in ordinary car-free days without organized events. Source: Author

From field notes and unstructured observation, organized events encourage improvisation of street elements such as benches and curbs (figure 4.2.4). Additionally, variations across user groups have a great effect on space use. For example, children tend to gather outside the Maruman Toy Shop; children also utilize the three steel benches on the street for play. Many youths gather outside the Game Taito Station and McDonalds; youthful audiences are also more engaged in the music performances than older ones. High school students are often in groups and improvise street elements such as curbs and bollards for sitting. For the elderly, most of their stay activities involve taking rest whereas many couples' stay activities are part of decision making.

There are also clear variations in behavior based on types of attractions on the street. Even among the music performances, differences are prominent. For example, rock bands attract more people than solo performances. Generally, stores with information (such as menus) and merchandise displayed outside especially restaurants and convenience stores have a greater pull than others; tobacco vending machines are additional sources of stay activities. Advertising staff such as those giving pamphlets outside shops are 
also key contributor to stay activities. The characteristics of the top three storefronts influencing constellation of stay activities are summarized in table 4.1.2
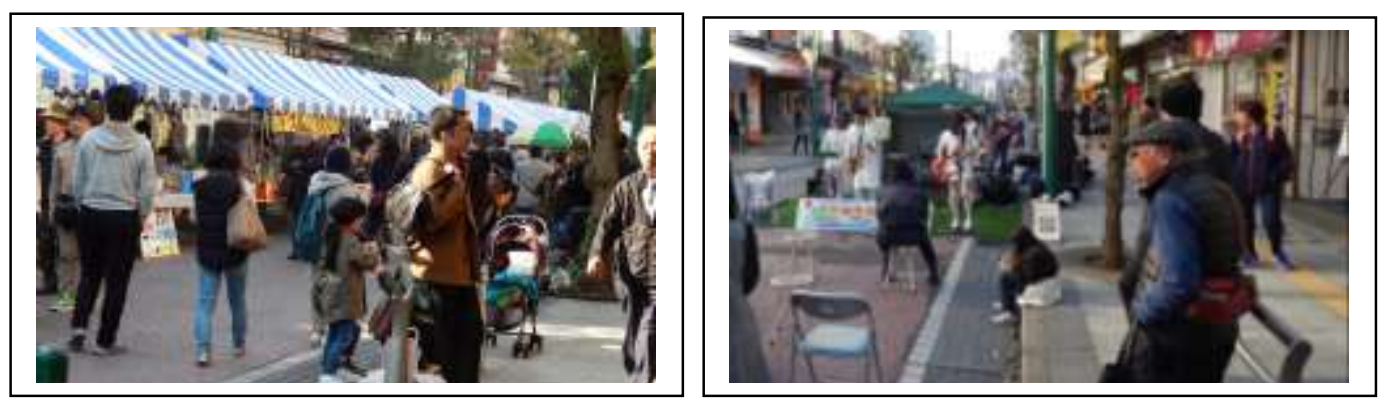

Figure 4.2.4: Emergent of unconventional use of street elements during organized events Source: Author

Table 3 Influence of shops on stay activities in Howdy-mall

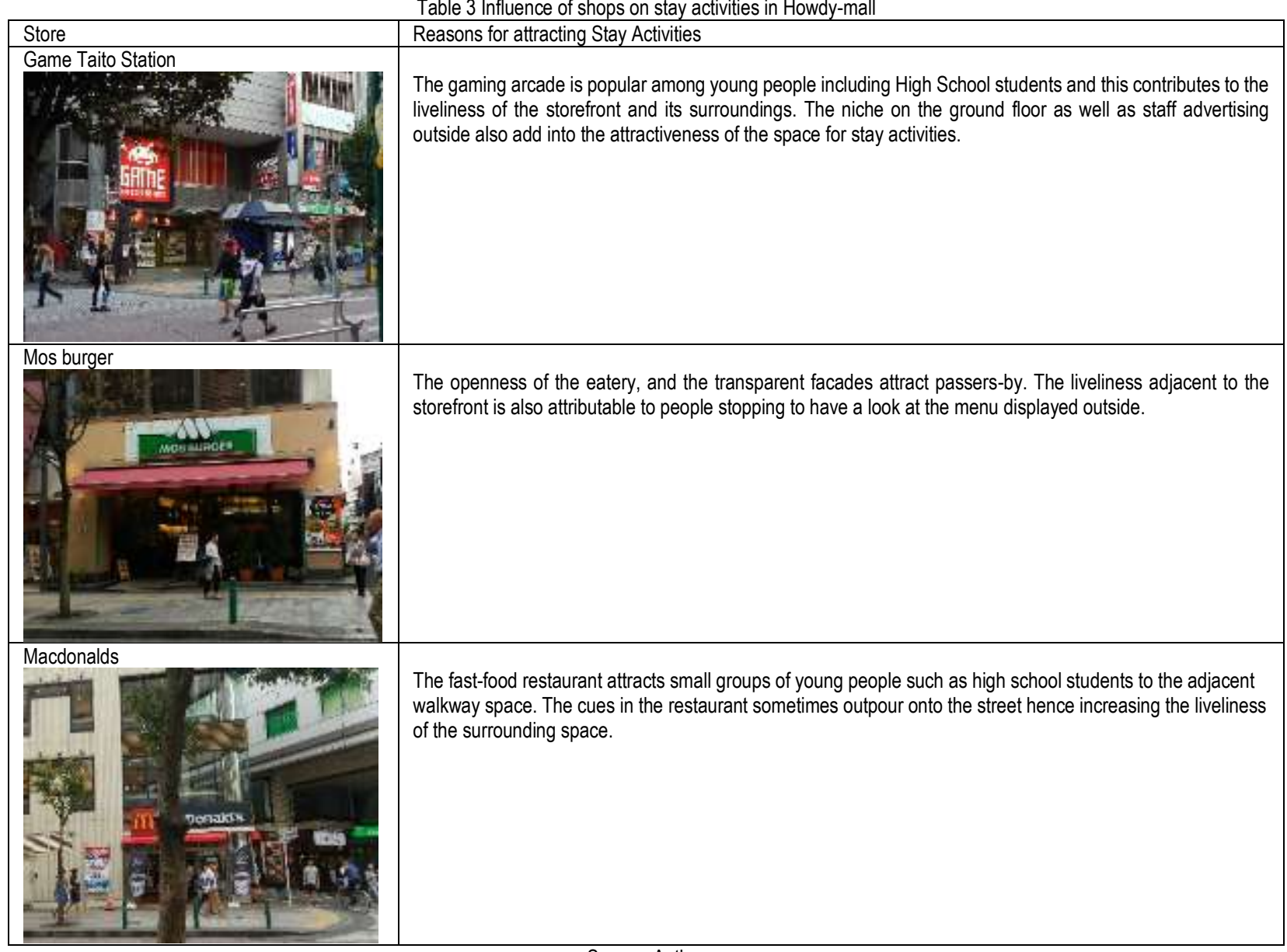

Source: Author

\subsection{Discussion}

The results above depict clear differences in the occurrence of stay activities in three situations: weekdays with cars passing, ordinary car-free Sundays, and car-free Sundays with organized activities. The influence of organized events is immense. Unfortunately, most organized events that have a significant influence on the liveliness of these streets also require massive preparations and funds while their cummulative influence on the use of car-free space in ordinary days is still indeterminate. In general, observed stay activities in our findings fall into three categories: 1. activities arising from pre-planned attractions such as street play and music performances; 2. Necessary stay activities related to shopping, and elements placed outside of shops, and 3., sporadic stay activities on the street such as a couple stopping briefly in the middle of the street or people squatting to interact with pets.

In both streets presented here, conversations on the streets are generally restricted to family, friends, and acquaintances. The absence of emergent conversations shows that individual objectives rarely merge into communal activities on the public space. It is 
clear that the automobile-oriented design and the insufficiency of facilities such as benches undermine outdoor life. With only a few permanent sitting areas, except for elderly or sickly pedestrians, sitting among adults is only visible during events when temporary sitting is availed and people adapt unconventional elements such as sitting on curbs and railings.

The function of stores, character of facades, and availability of niches are additional contributors to the occurrence of stay activities. Moreover, the physical character and function of stores vary depending on the day of the week as well as minor changes in arrangement and activities on the storefront. For example, the open display in Itoyokado Supermarket along Howdy-mall changes almost every weekend; selling second-hand CDs and DVDs has a greater contribution to liveliness as compared to selling food. Involvement of business owners in street space includes advertising the events to their customers, funding of play leaders and provision of furniture for events, organizing stay activities related to their businesses, as well as advertising their business to participants.

There are clear variations in stay activities based on age, gender and other characteristics inherent in street users. For example, improvisation of undesignated sitting opportunities such as curbs and bollards are generally limited to youths and children while adults only utilize them during organized events.

\subsection{Conclusion}

At the outset of this discourse, this study theorized that temporary restriction of cars presents an opportunity for the reinterpretation of the street space from being a channel for movement into its consideration as an urban open space for stationary activities. It is evident that restricting cars has not been succeeded by utilization of the emergent space for stay activities. Nevertheless, events such as playstreet rekindle the importance of car-free streets as platforms for stay activities. The innovative use of space for activities such as sitting and eating during events is a strong indication of people's aspirations to use available space. The intent is seemingly frustrated by the lack of incentives necessary to invite people into and to keep them on the street space. Ultimately, piecemeal initiatives by residents and shop owners will play a critical role in establishing liveliness of street spaces in a way that is beneficial to businesses and local residents. Children's playstreet, and music performances recorded in this study point to the effect of various incentives necessary to maximize street use.

The study contributes to current knowledge on the micro-scale relationship between car-free street space and stay activities, the implication of organized activities, as well as the role of shop owners in the liveliness of adjacent street spaces. The study also opens debate on the ability of shopping streets to support stay activities of varying user groups such as the elderly and children. The results of this study being cross-sectional are limited in explaining the changes that have been occurring in the nature of stay activities in these streets over time. Future studies on stay activities will be instrumental in demonstrating the adaptability of these results in other shopping streets in Japan, the time-series changes, and the prospects for the future regarding the significance of shopping streets as urban open spaces.

\section{Acknowledgments}

This study was done under the Japanese Government (MONBUKAGAKUSHO: MEXT) Scholarship.

\section{References}

Abu-Ghazzeh, T. M. (1998). Children's use of the street as a playground in Abu-Nuseir, Jordan. Environment and Behavior, 30(6), $799-831$.

Carlin, A. (2014). Working the crowds: Street performances in public spaces. In City Imaging: Regeneration, Renewal and Decay (pp. 157-169). Springer, Dordrecht.

Chen, Y., Nakamura K., and Kengo, K. (2014). Identification of street affordances by evaluating street elements in Shanghai. Journal of Architecture and Planning, Architectural Institute of Japan. Volume 79 No. 705, 2487-2496

Gehl, J., \& Svarre, B. (2013). How to study public life. Washington: Island Press

Gehl, J. (2011). Life between buildings: using public space. Washington: Island Press

Gold, R. L. (1997). The ethnographic method in sociology. Qualitative inquiry, 3(4), 388-402.

Hou, J. (2012). Making public, beyond public space. Beyond Zuccotti Park: Freedom of assembly and the occupation of public space, $89-98$.

Ja'afar, N. H., Sulaiman, A. B., \& Shamsuddin, S. (2018). landscape features and traditional streets character in Malaysia. Asian Journal of Environment-Behaviour Studies, 3(8), 121-131.

Lee, D., \& Yoon, C. J. (2015). Sequential Analysis on the Intensity of Store Information to the Commercial Street-from the Viewpoint of Pedestrian Movement. Journal of Asian Architecture and Building Engineering, 14(3), 617-624.

Mehta, V. (2014). Evaluating public space. Journal of Urban Design, 19(1), 53-88.

Ujang, N. (2017). Place Attachment and Continuity of Urban Place Identity. Asian Journal of Environment-Behaviour Studies, 2(2), 117-132.

Zakaria, J., \& Ujang, N. (2015). Comfort of walking in the city center of Kuala Lumpur. Procedia-Social and Behavioral Sciences, 170, 642-652. 